\title{
Development of a highly productive GMAW hot wire process using a two-dimensional arc deflection
}

\author{
E. Spaniol ${ }^{1} \cdot$ M. Trautmann ${ }^{1} \cdot$ T. Ungethüm ${ }^{1} \cdot$ M. Hertel ${ }^{1} \cdot$ U. Füssel ${ }^{1} \cdot$ P. Henckell ${ }^{2} \cdot$ J. P. Bergmann $^{2}$
}

Received: 9 September 2019 / Accepted: 2 March 2020 / Published online: 21 March 2020

(C) The Author(s) 2020

\begin{abstract}
Gas metal arc welding (GMAW) processes are used in a wide range of applications due to their high productivity and flexibility. Nevertheless, the supplied melting wire electrode leads to a coupling of material and heat input. Therefore, an increase of the melting rate correlates with an increase of the heat input by the arc at the same time. A possibility to separate material and heat input is to use an additional wire, which reduces penetration and worsens the wetting behaviour. Consequently, bead irregularities such as bonding defects or insufficient root weldings can occur. In the context of this article, a controlling system for a two-dimensional magnetic arc deflection is presented, which allows to influence arc position as well as material transfer. The analysed GMAW hot wire process is characterised by high melting rates while also realising a sufficient penetration depth and wetting behaviour.
\end{abstract}

Keywords Gas metal arc welding $\cdot$ Hotwire $\cdot$ Two-dimensional magnetic arc deflection $\cdot$ High productive welding

\section{Introduction}

Gas metal arc welding (GMAW) is used in many fields like machine and plant construction, automotive applications or the offshore industry due to its high productivity and direction independence. In the past, the development of high-performance processes using multiwire technology increased the deposition rate and thus the productivity significantly [1-3]. However, the application of GMAW high-performance processes using multiple arc-conducting electrodes, such as tandem welding or double wire welding, always involve a high heat input into the base material due to the coupling of heat input and filler wire supply. Consequently, the requirements regarding the mechanicaltechnological properties cannot be fulfilled sufficiently due to coarse grain formation $[4,5]$. In addition, the high time and location-dependent heat input leads to an increase of residual

Recommended for publication by Commission XII - Arc Welding Processes and Production Systems

E. Spaniol

erik.spaniol@tu-dresden.de

1 TU Dresden, Faculty of Mechanical Science and Engineering, Chair of Joining Technology and Assembly, Institute of Manufacturing Technology, Dresden, Germany

2 Department of Production Technology, Faculty of Mechanical Engineering, TU Ilmenau, Ilmenau, Germany stresses and distortion, so that time and cost consuming preand posttreatments (preheating, postheating, straightening, rolling) are necessary to achieve a high geometrical accuracy. Although the development of modified spray and pulse arc processes allows to influence the process behaviour by controlling the arc dynamics [6], the potential of high-performance processes can still not sufficiently be used. The use of arcless additional wires offers the possibility to minimise the thermal influence on the base material while simultaneously increasing the deposition rate, since a decoupling of heat and material supply can be achieved $[2,3,7]$. However, the achievable productivity increases are relatively low, since the supply of the arcless wire involves a significant cooling of the melt pool. The reduction of the mean melt pool temperature leads to a significant reduction of penetration and worse wetting behaviour, resulting in root and bonding defects (see Fig. 1). Therefore, it is not possible to guarantee a high quality weld with regard to a sufficient corrosion resistance as well as high strength of the welded joint. In addition, the mechanical properties are influenced by the high cooling rates [8-10].

\section{Research goals}

An increased melting rate with simultaneously reduced heat input can be achieved by adapting the temperature distribution at the workpiece. This allows controlling penetration and 
Fig. 1 Influence on penetration, wetting behaviour and microstructure using GMAW hot wire welding for deposition of the wear protection alloy FeV12 [10]

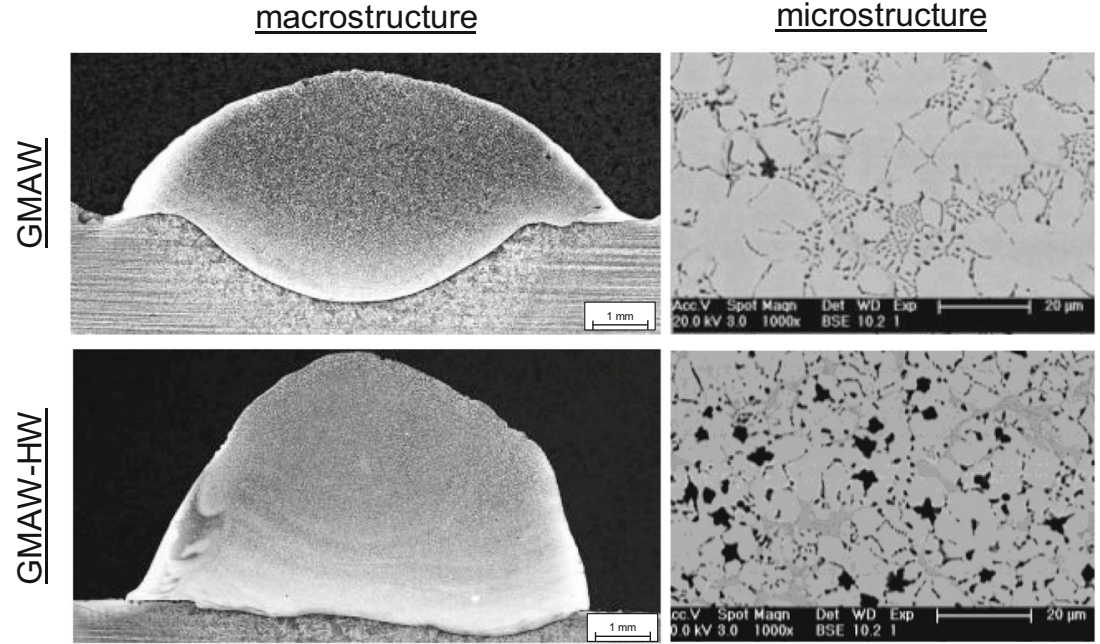

wetting conditions as well as influencing the mechanicaltechnological properties. In addition, a reduction of residual stresses and distortion is possible. The adjustment of the thermal field can be achieved by combining a GMAW hot wire process with a two-dimensional magnetic arc deflection, (see Fig. 2). This makes it possible to increase process stability and productivity, while at the same taking material properties into account.

The possibility to adjust the heat field is especially important for the processing of temperature-sensitive materials such as austenitic steels, titanium or nickel-based alloys. In

arc deflection transverse the travel direction

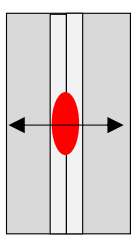

Decrease of penetration

Improvement of wetting behavior

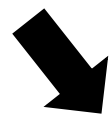

two-dimensional arc deflection

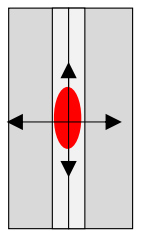

Increase of penetration

Improvement of wetting behavior

Fig. 2 Use of an adapted heat field by a two-dimensional arc deflection to optimise penetration and wetting behaviour addition, it is possible to reduce operating costs by substituting cost-intensive shielding gases. Those gases are necessary in conventional GMAW hot wire processes to increase the melt pool temperature and consequently the heat input. Therefore, a reliable penetration, reproducible root bonding and sufficient wetting behaviour can be guaranteed while also allowing the reduction of layers during joint welding of large sheet thicknesses (see Fig. 3). As a result, the total heat input and thus the formation of residual stresses and distortion can be reduced. This leads to a reduction of rework effort ensuring a higher economic efficiency.

\section{Development of a two-dimensional magnetic deflection unit}

Within the scope of the presented research work, a deflection unit was developed, which consists of a torch attachment for a two-dimensional arc deflection as well as a controlling system. The magnetic deflection device was designed in such a way that it can be easily adapted to existing GMAW torch systems so that it can be used for both conventional GMAW welding as well as GMAW hot wire processes. Great attention was paid to fulfil the requirements regarding a small size and improved accessibility as well as easy handling. For this purpose, the pole shoes for transmitting the magnetic field into the process zone were integrated into the gas nozzle (see Fig. 4), so that the pole shoes are cooled by heat conduction. The cross section of the pole shoes along the gas nozzle is $15 \mathrm{~mm}^{2}$. In the area of the arc, a reduced pole shoe crosssection of $9 \mathrm{~mm}^{2}$ has been realised to ensure sufficient accessibility of the hot wire supply. The distance between two opposite pole shoes is $15 \mathrm{~mm}$. For the investigations, 4 identical coils each with 40 windings per layer and 6 layers were produced with a coil winding machine (overall 240 windings). The two-dimensional arc deflection is achieved by the 
Fig. 3 Influence of a static magnetic arc deflection in welding direction on the weld pool surface, the material transfer and the root formation (material: 1.4301; wall thickness: $5 \mathrm{~mm}$; butt joint with V-seam preparation)

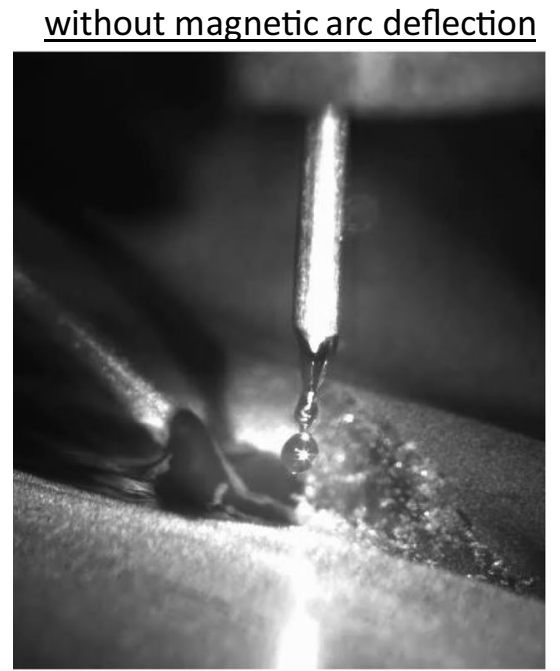

\section{with magnetic arc deflection}

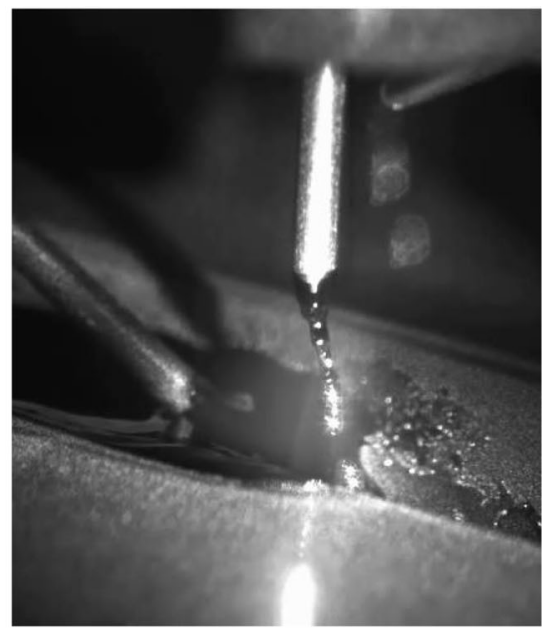

root defects
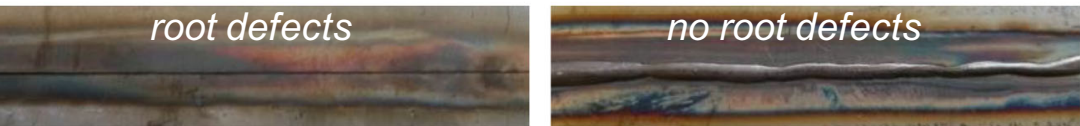

$$
\begin{array}{ll}
\mathrm{I}_{\mathrm{GMAW}}=300 \mathrm{~A} & \mathrm{I}_{\mathrm{HW}}=190 \mathrm{~A} \\
\mathrm{v}_{\mathrm{GMAW}}=10 \mathrm{~m} / \mathrm{min} & \mathrm{V}_{\mathrm{HW}}=7 \mathrm{~m} / \mathrm{min}
\end{array}
$$

superposition of the magnetic fields of two water-cooled coil pairs, which have an offset of $90^{\circ}$ to each other (see Fig. 4).

The level and frequency of the coil current of each coil pair can be regulated individually, so that different deflection patterns can be realised. Therefore, a linear, circular, elliptical or quadratic movement of the arc can be achieved, but also asymmetric deflection patterns can be generated. The deflection patterns result from the superposition of transient current patterns of both coil pairs. Thus, it is possible to deflect the arc with regard to time and location. The controlling unit adjusts the process parameters and visualises the deflection patterns. The coils are mounted at the upper end of the gas nozzle to ensure a sufficient accessibility in constrained positions. The resulting local separation of the generation of the magnetic field and the operating range in the process area ensures that the gas nozzle can be easily replaced in case of pollution (see Fig. 4). For this purpose, the gas nozzle consists of two parts. The lower part of the gas nozzle, which is subjected to high thermal wear, is passively cooled by heat conduction. The coils and the upper part of the gas nozzle exhibit an active water cooling, being also responsible for the cooling of the components of the magnetic circuit. In order to ensure optimum shielding gas coverage, the internal geometry of the gas nozzle has been designed in such a way that it corresponds to
Fig. 4 Torch attachment for twodimensional arc deflection during GMAW hot wire welding (left) and magnetic circuit (right); opposite coils (A-C and B-D) form one coil pair
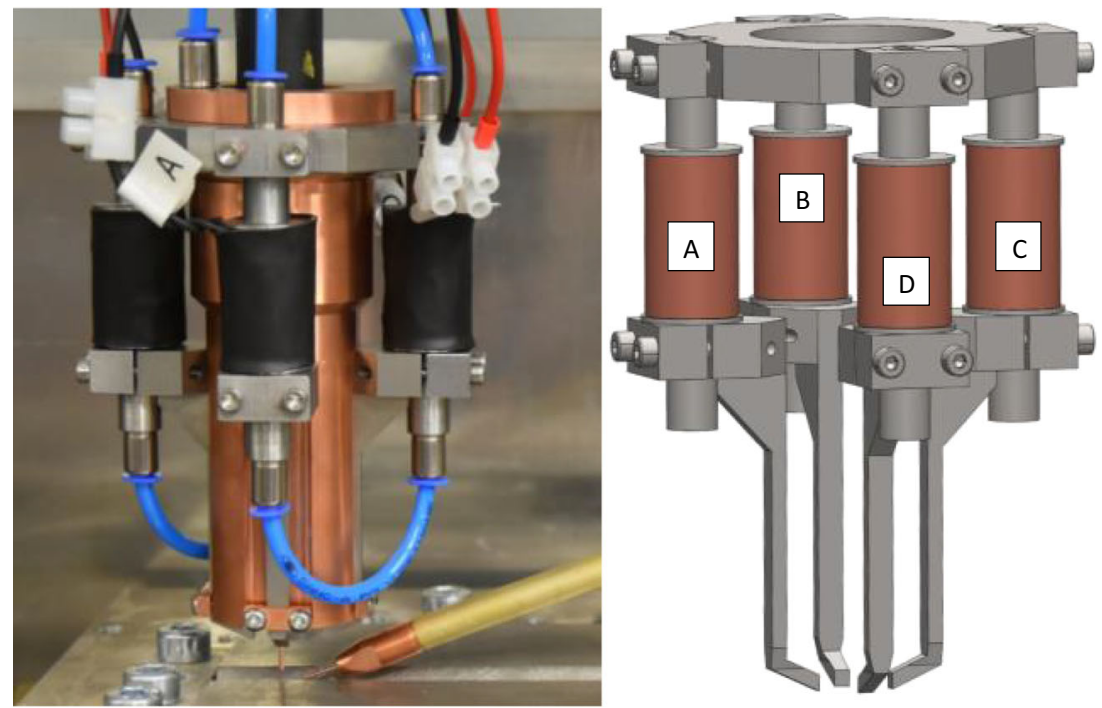
the internal geometry of a conventional conical gas nozzle of the flush type by Abicor Binzel. The developed magnet unit was adapted to a push-pull welding torch of the type ROBO WH-PP W500 that is also produced by Abicor Binzel. The magnet unit is characterised by a high geometrical variability and flexibility to investigate coils of different lengths as well as different numbers of layers and windings. In addition, it is possible to vary the geometry as well as the position of the pole shoes to influence the magnet field in the process area.

\subsection{Electromagnetic field formation}

Figure 5 illustrates schematically the formation of the magnetic field in the process area between two pole shoes. Furthermore, the correlation of coil current and magnetic field as well as the dependence of the magnetic induction on the position in the magnetic field is considered (see Figs. 6 and 7). The process behaviour depends on a large number of influencing factors such as wire diameter and material of the coils, the number of windings and layers, the core diameter and material of the coils, the shape and material of the pole shoes as well as the temperature and the magnetic permeability itself. In addition, the type and shape of base material and the additional wire material play an important role.

A stickout of $15 \mathrm{~mm}$ and a free wire length of $10 \mathrm{~mm}$ were assumed for the investigations, so that a distance of approximately $5 \mathrm{~mm}$ from the end of the arc-guiding wire electrode to the base material surface is achieved. To measure the magnetic field, a magnetic field metre with automatic temperature compensation was used. Due to the compact design of the measuring device, it is possible to insert the measuring tip in the process area between the free end of the wire electrode tip and the base material to measure the magnetic induction depending on the location in the magnetic field. The corresponding coordinates and planes are shown in Fig. 5. The origin of the coordinates is represented by the end of the free wire electrode. As shown in Fig. 6, the magnetic induction decreases

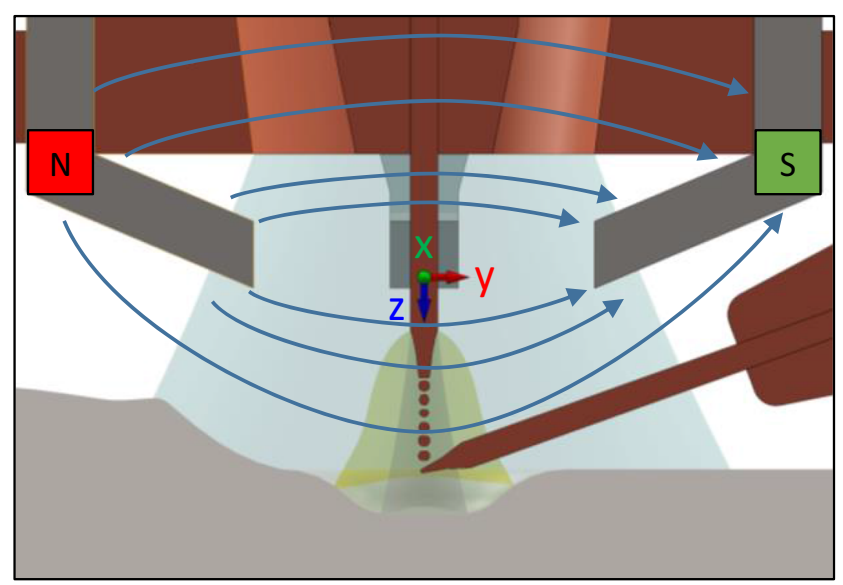

Fig. 5 Schematic formation of the magnetic field in the process area between a coil pair

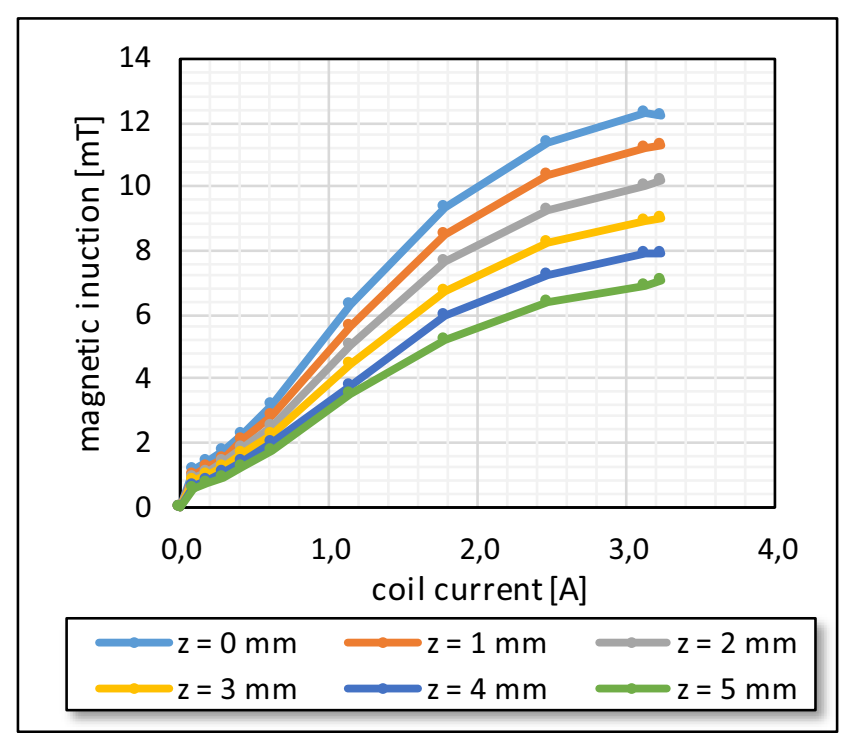

Fig. 6 Variation of the magnetic field between the free wire end and the base material surface

if the distance to the electrode tip is increased. The higher the coil current and thus the generated magnetic field, the higher is the drop of the magnetic induction if the distance to the electrode tip is increased. For the coil pairs, a drop of the magnetic induction from approximately $12.0 \mathrm{mT}$ directly at the end of the wire electrode between the two pole shoes $(z=0 \mathrm{~mm})$ to $6.8 \mathrm{mT}$ on the base material surface $(z=5 \mathrm{~mm})$ can be investigated using a coil current of $3.0 \mathrm{~A}$. A degressive relationship of coil current and magnetic induction can be recognised since the material of the magnetic circuit reaches magnetic saturation if high magnetic inductions are realised (see Fig. 6).

In contrast to the distance along the wire axis ( $z$ coordinate, see Fig. 5), the lateral distance to the wire axis has a much smaller influence on the magnetic field. The magnetic

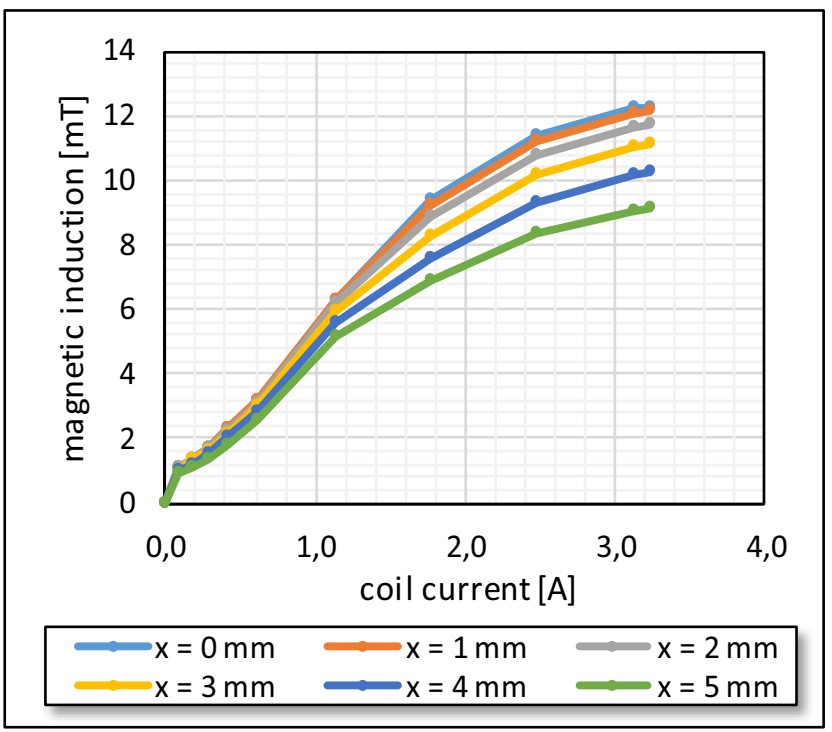

Fig. 7 Influence of the distance to the arc axis on the formation of the magnetic field 
induction of the coil pairs decreases from $12.0 \mathrm{mT}$ at a coil current of approximately $3.0 \mathrm{~A}$ in the central axis $(x=0 \mathrm{~mm})$ between the two pole shoes to $8.8 \mathrm{mT}$ at a distance of $5 \mathrm{~mm}$ (see Fig. 7). This corresponds to a drop of about $14 \%$.

\subsection{Influence of the magnetic deflection on the shielding gas coverage}

To prove the functional capability of the developed demonstrator and to get a first qualitative impression of the influence of the two-dimensional magnetic arc deflection on the shielding gas coverage, high-speed imaging was applied using Schlieren technique in a Töpler-Z-arrangement [11-13]. This measuring method is based on the visualisation of shielding gas flows using the densitydependent refractive index. If shielding gases with a large density difference to the surrounding atmosphere are used, a strong deflection of the light rays of a lighting source can be achieved. Thus, streaks occur and the shielding gas flow can be qualitatively evaluated. To minimise the experimental effort, tungsten electrodes with a diameter of $2 \mathrm{~mm}$ were pressed into conventional contact nozzles for a wire diameter of $1.2 \mathrm{~mm}$. A free wire electrode end of $10 \mathrm{~mm}$ was realised. The shape of a wire end during GMAW welding with spray arc using argon-rich mixed gases was simulated. The experiments were carried out with a direct current of 200 A using a negatively poled electrode (DC-). For the investigations, a ArHe-mixture with $70 \%$ helium was used and a flow rate of $15 \mathrm{l} / \mathrm{min}$ was applied. The arc was deflected with a magnetic induction of approximately $2.15 \mathrm{mT}$ and rotated with a circular frequency of $1 \mathrm{~Hz}$. Figure 8 shows the flow and turbulence behaviour of the shielding gas flow in $90^{\circ}$ intervals.

It becomes clear that the dynamic two-dimensional deflection of the arc leads to an irregular shielding gas distribution. Since the arc position changes permanently, pressure differences occur in the shielding gas flow leading to vortex formation (see Fig. 8). However, turbulence formation only occurs outside the process area. In the arc area, the formation of a laminar shielding gas flow can be observed, so that a sufficient gas shielding can be assumed.

Since the Schlieren technique cannot clarify to what extent the dynamic flow behaviour influences the quality of the shielding gas coverage and thus the protection of electrode, melt pool and base material, the oxygen concentration was measured as function of the circular frequency at the projected foot point on the workpiece surface below the electrode (see Fig. 9). The measurement method used is based on the lambda probe principle [12-14]. Therefore, a measuring volume flow is extracted through a measuring bore (diameter approximately $0.5 \mathrm{~mm}$ ) in a water-cooled copper plate, which is then

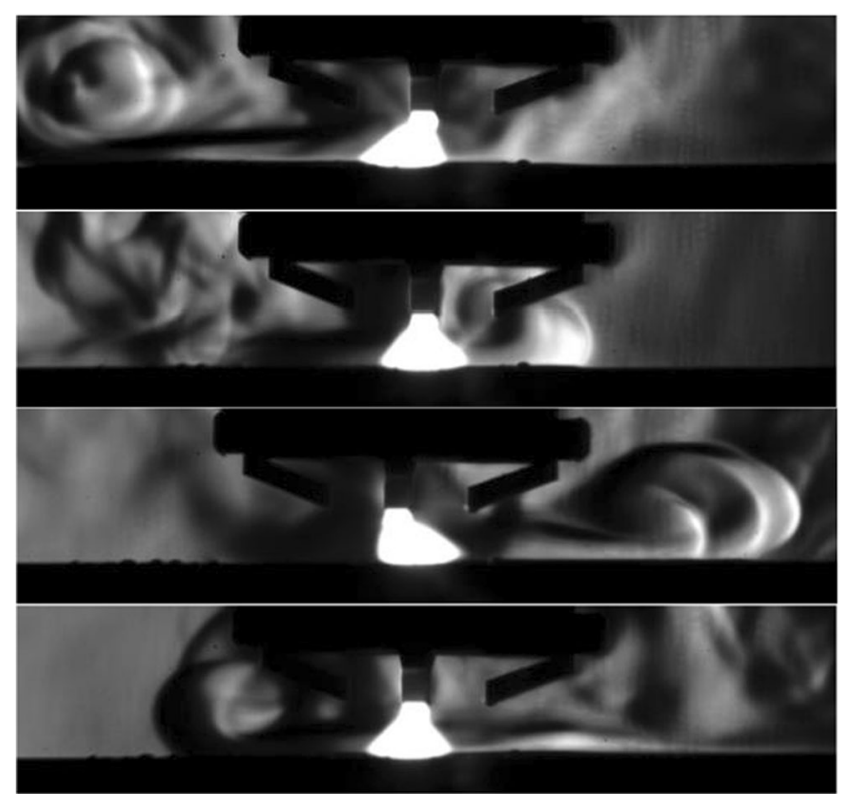

Fig. 8 Qualitative evaluation of the shielding gas flow using Schlieren technology for a rotating arc

conducted into the lambda sensor. In the lambda probe, free oxygen atoms are ionised by the impact of electrons emerging from hot platinum electrodes. Through the directional movement of the charged particles, corresponding to an applied electrical potential, a voltage can be detected, which varies depending on the oxygen concentration (variation of the quantity of oxygen ions). By evaluating the measured voltage, the oxygen concentration in the process area is determined. In contrast to the Schlieren experiments, $100 \%$ Ar with a flow rate of $201 / \mathrm{min}$ was

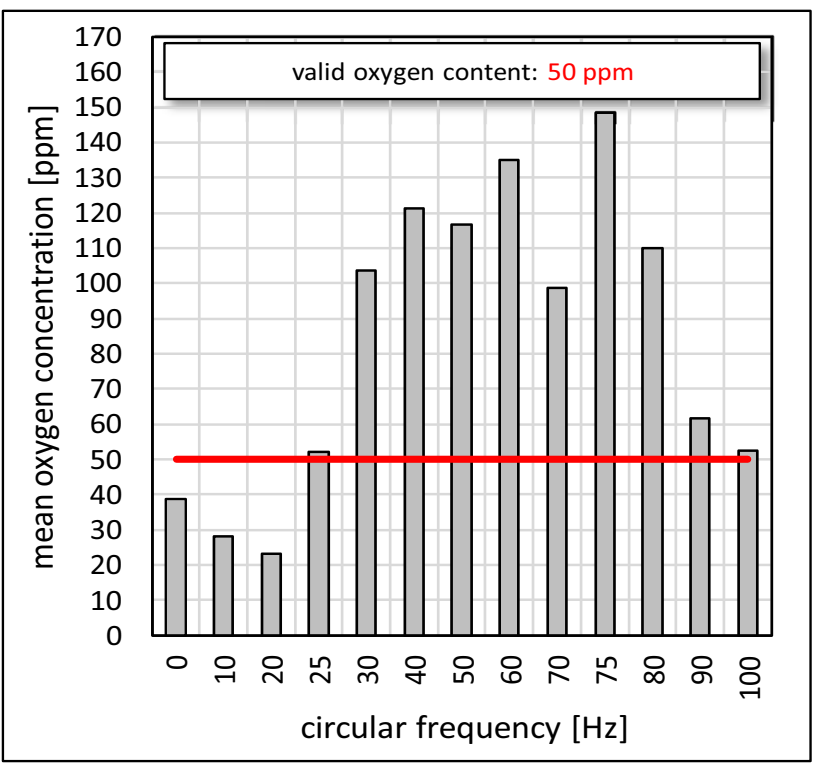

Fig. 9 Influence of the circular frequency on the oxygen concentration in the shielding gas at the projected foot point of the wire electrode 
used as shielding gas for the measurement of the oxygen concentration.

As shown in Fig. 9, it becomes clear that low circular frequencies of the magnetic field of up to $20 \mathrm{~Hz}$ can guarantee an oxygen concentration of under $50 \mathrm{ppm}$ and thus ensuring a sufficient shielding gas coverage. If the frequency is further increased, the valid oxygen concentration is exceeded because of the increasingly turbulent shielding gas flow (see Fig. 9). This increases the risk of undesirable oxidation. From a circular frequency of approximately $75 \mathrm{~Hz}$, there is a decrease of the occurring oxygen concentration (see Fig. 9). In this case, the inductivity of the coils prevents a sufficient magnetic arc deflection since the magnetic field cannot change fast enough. Additional line measurements underline this assumption (see Fig. 10). These experiments were carried out at different circular frequencies of the arc to evaluate the shielding gas distribution.

It becomes obvious that up to a circular frequency of approximately $10 \mathrm{~Hz}$, sufficient shielding gas coverage can be achieved to a distance of maximum $4 \mathrm{~mm}$ from the electrode axis. This corresponds to the process range in which the valid oxygen concentration can be maintained even without an arc deflection. Nonetheless, the oxygen concentration generally increases slightly when the arc is deflected two-dimensionally. From a circular frequency of about $20 \mathrm{~Hz}$, the existing oxygen concentration exceeds the threshold value of $50 \mathrm{ppm}$. The oxygen concentration rises continuously up to a circular frequency of $80 \mathrm{~Hz}$ (see Fig. 10). If the circular frequency is further increased, the oxygen concentration decreases again. The results show that the application of a maximum deflection frequency of $20 \mathrm{~Hz}$ is appropriate for further investigations.

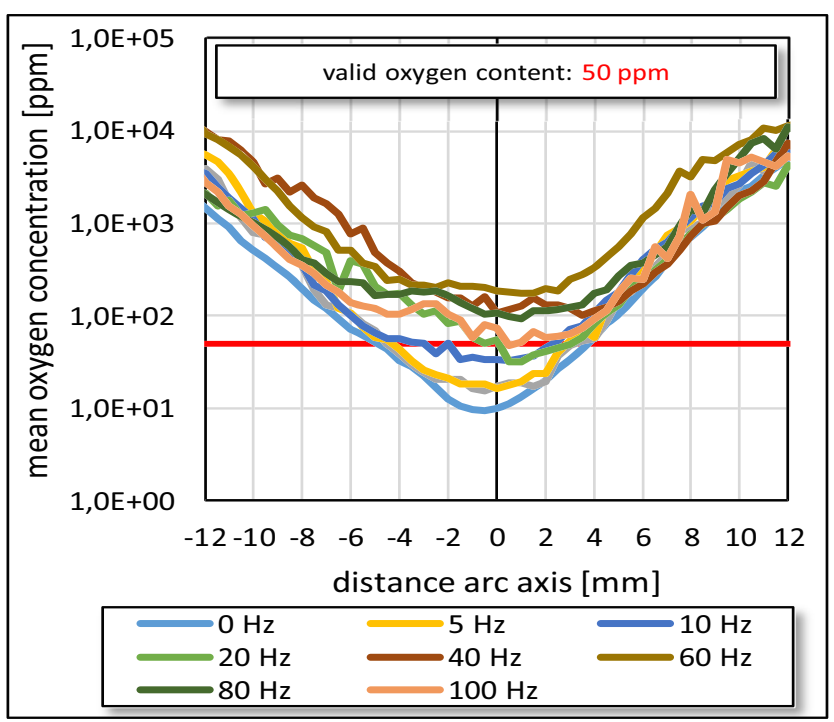

Fig. 10 Influence of the circular frequency on the oxygen concentration in the shielding gas as a function of the distance to the arc axis

\section{Two-dimensional arc deflection in combination with GMAW hot wire welding}

\subsection{Calculation of the heat input through numerical simulations}

To analyse the influence of process parameters on the heat input into the base material, a three-dimensional MHD arc model was adapted. The model includes the essential process components - a GMAW wire electrode, a hot wire electrode, the base material and the shielding gas region, see Fig. 11. In order to reduce the complexity of the model, the base material and wire electrodes are assumed as solid with a stationary shape. The droplet detachment at the wire electrode is not taken into account.

It is expected that the gaseous phase of the process area can be sufficiently described by a mixture of argon and iron. The iron arises through the evaporation of the GMAW wire electrode under the assumption of a temperature profile with an assumed maximum temperature of $3000 \mathrm{~K}$ at the wire tip [15]. The influence of the magnetic field due to the hot wire current is considered by an additional source term in the equations of the magnetic vector potential in the calculation area of the hot wire. Furthermore, a $\mathrm{P}_{1}$ radiation model was included, which considers the radiative transfer in the process region [16]. Besides the spatial approximation by the $\mathrm{P}_{1}$ model, a spectral approximation consisting of six bands is applied. The required absorption coefficients and blackbody functions in the model are calculated analog to the thermophysical properties depending on both temperature and iron concentration.

The numerical investigations were used to calculate the heat distribution at the base material - especially on the upper sheet region, the seam flank and the root area of the seam. Those investigations were carried out using different twodimensional magnetic deflection profiles. To reduce the calculation complexity, only stationary deflections of the arc were considered. In the welding process, these states can be controlled time-dependently. For the results, a process with a current of $300 \mathrm{~A}$, a wire feeding rate of the GMAW wire electrode of $10 \mathrm{~m} / \mathrm{min}$ and an argon shielding gas flow rate of $12 \mathrm{l} / \mathrm{min}$ were considered. Figure 12 shows the influence of the arc deflection on the distribution of the total heat flux at the base material surface for different superimposed constant magnetic fields.

If no magnetic field is applied, the arc attaches mainly the edges of the upper sheet. As a result, the seam flanks cannot be sufficiently melted. When the arc is deflected in welding direction, less heat is introduced into the upper sheet region but more heat is applied to the seam flanks, since the arc can be shifted onto it (see Fig. 13). This effect can be supported by additionally deflecting the arc 
Fig. 11 Computational domain of the process model
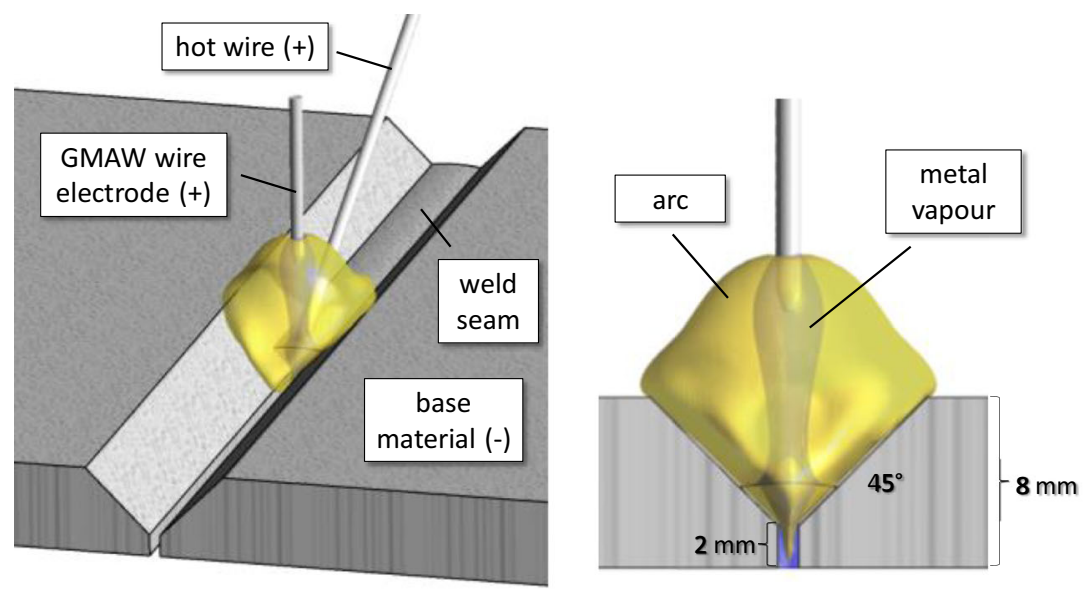

transverse to the welding direction. Both effects can significantly reduce the risk of cold shuts.

In addition to the shift of the heat input into the flanks, the total heat input is additionally increased by the deflection along the welding direction. This originates mainly from the increase of the heat input due to heat conduction caused by the higher contact surface between arc and base material for a deflected arc. For an arc deflection with a magnetic field of $5 \mathrm{mT}$ in welding direction, approximately $860 \mathrm{~W}$ are introduced by heat conduction, $830 \mathrm{~W}$ by heat radiation from the arc and $3600 \mathrm{~W}$ by heating in the sheath area of the cold cathode [17]. Without the arc deflection, approximately $560 \mathrm{~W}$ is transmitted by heat conduction.

When considering the deflected arc, it must also be taken into account that the material transfer is shifted, which also has a positive influence on the flank wetting behaviour. The heat input through the material transfer is not considered in the presented model.

\subsection{Experimental investigation of process, penetration and wetting behaviour}

To investigate the potential of a GMAW hot wire process combined with an external two-dimensional arc deflection, joint welds with 8-mm thick sheets out of S355JR were examined. Therefore, a Y-seam preparation with $45^{\circ}$ opening angle and a web of $2 \mathrm{~mm}$ were applied (see Fig. 11). For the process analysis, high-speed imaging was executed and cross sections were prepared.

It became clear that a significant electromagnetic blowing effect occurs due to the hot wire current (see Fig. 14). Thus, both arc and the droplet transfer are shifted in the direction of the hot wire. Consequently, a large amount of heat is introduced into the melt pool instead of the unmolten base material leading to a worse penetration and wetting behaviour.

In case of a GMAW hot wire process with a wire feeding rate of $10 \mathrm{~m} / \mathrm{min}$, pores can occur since the melt pool is cooled
Fig. 12 Influence of the arc deflection on the heat flux distribution at the base material surface for different superimposed constant magnetic fields
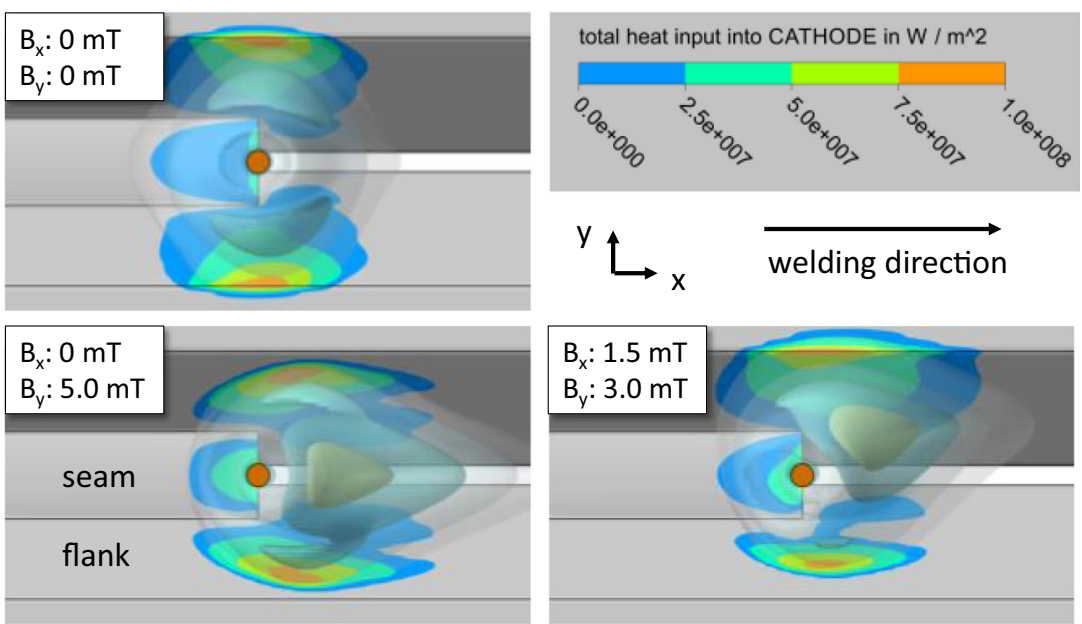


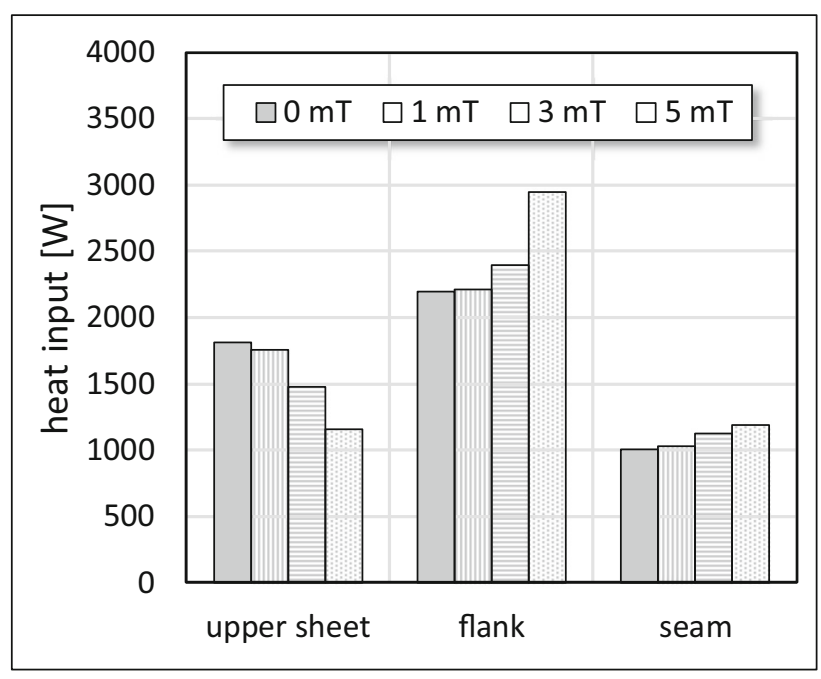

Fig. 13 Influence of the arc deflection in welding direction on the heat input into the base material for different superimposed constant magnetic fields

significantly through the hot wire feeding. To avoid pore formation, the GMAW wire feeding rate and therefore the GMAW current has to be increased. Nevertheless, this cannot improve the penetration depth significantly (see Fig. 14). Furthermore, there is a reduced process stability and a higher probability of spatter formation due to the magnetic blowing effect through the hot wire feeding.

To increase the penetration depth and decrease the contact angle, a one-dimensional external magnetic field can be applied leading to magnetic force longitudinal to the travel direction (see
Fig. 15). However, the probability of pore formation is still high since the weld pool cannot be heated sufficiently. To prevent pore formation, a magnetic arc deflection transverse to the travel direction is of advantage. Nevertheless, this also leads to a reduction of the penetration depth (see Fig. 15).

To combine the advantages of a transverse and longitudinal arc deflection, two external magnetic fields can be superimposed. By the adjustment of the coil currents and the coil frequencies of two coil pairs, it is possible to change the position of the arc at a specific location and time and thus control the local heat input.

In addition to a higher process stability, a two-dimensional magnetic arc deflection can improve the outer bead appearance especially during the starting process. Figure 16 shows that a uniform outer seam appearance can be achieved during deposition welding by rotating the arc. Furthermore, it is possible to shorten the process settling times and reduce the risk of starting binding defects. Besides that, a significant reduction of silicate formation can be observed, resulting in advantages regarding multilayer welding as the risk of ignition problems is reduced.

In case of joint welding, different deflection patterns can be applied to improve the seam quality. If the arc is deflected stationary longitudinal to the travel direction and oscillated periodically transverse to the travel direction, the wetting behaviour can be improved, increasing the penetration depth at the same time (see Fig. 17 left). If the arc is additionally oscillated longitudinal to the travel direction, a further increase of penetration can be achieved (see Fig. 17 right).
Fig. 14 Process behaviour and macrostructure using different GMAW wire feeding rates for GMAW hot wire welding of a butt joint with Y-seam preparation

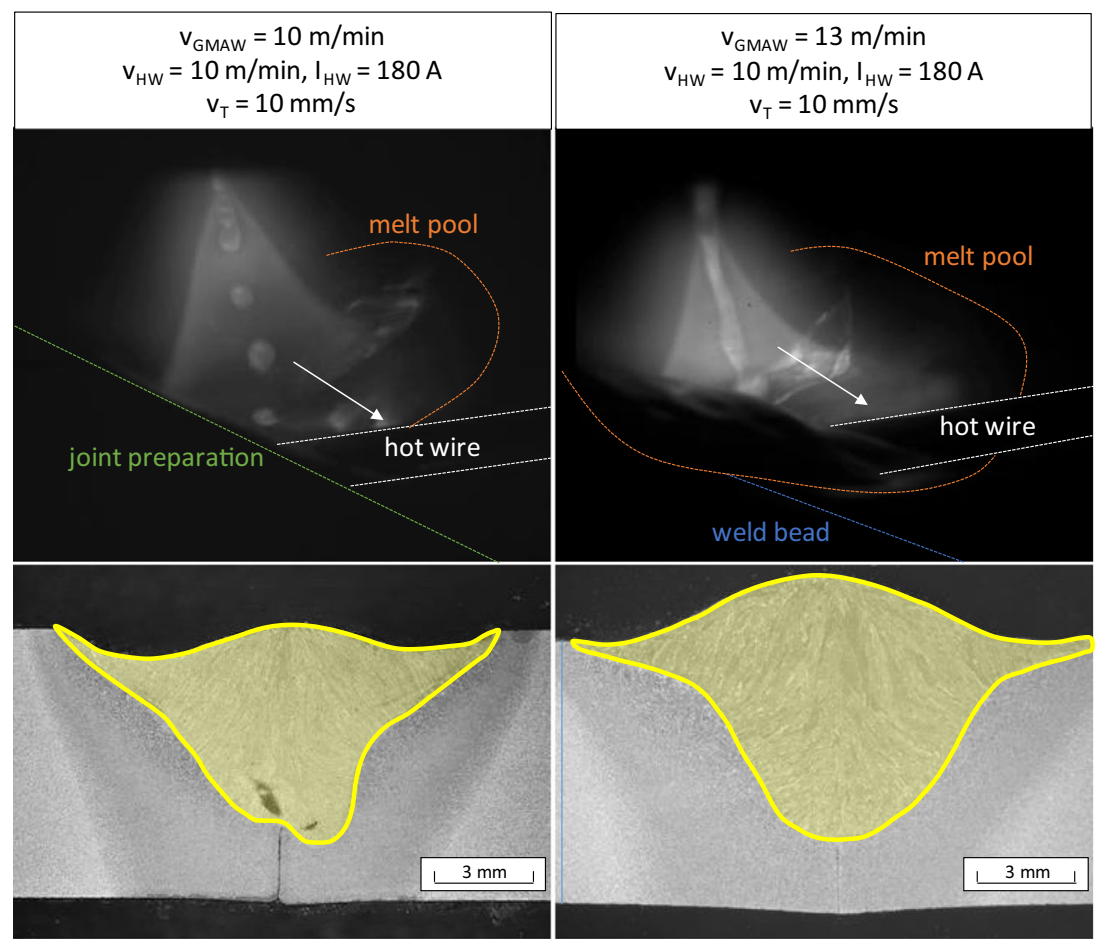


Fig. 15 Process behaviour and macrostructure using transverse or longitudinal arc deflection for GMAW hot wire welding of a butt joint with Y-seam preparation

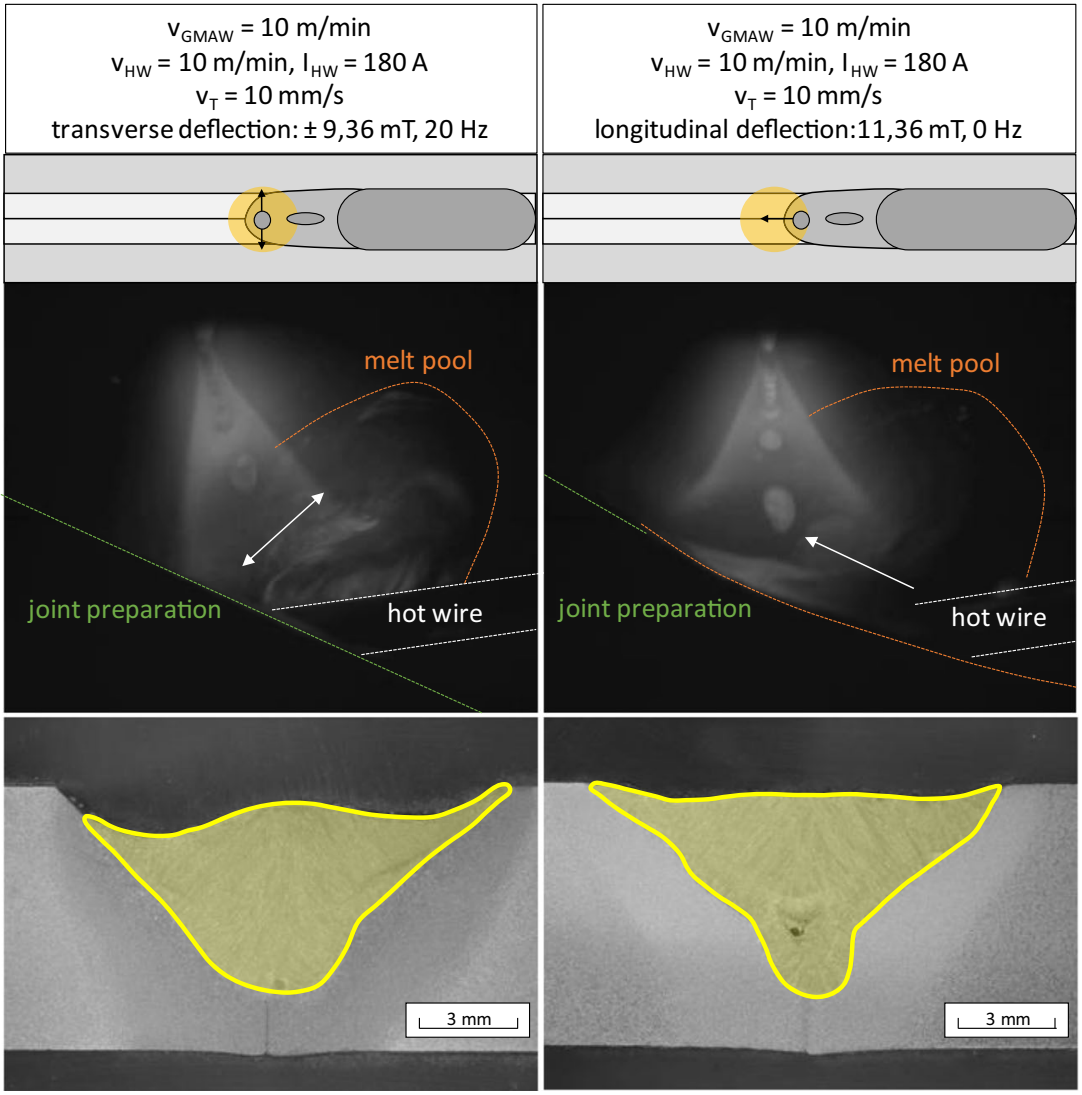

Nevertheless, a sufficient root welding comparable with the welding of a butt joint with V-seam preparation in Fig. 3 is not possible, since a higher amount of additional material is introduced through the hot wire leading to a highly dynamic weld pool behaviour.

\section{Summary, conclusion and outlook}

The presented research work deals with the development of a high-performance welding process for joint welding. Therefore, GMAW hot wire welding is combined with a

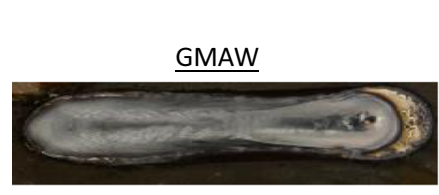

GMAW + 2D arc deflection (rotation)

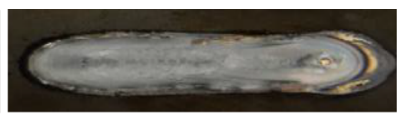

GMAW-HW +

GMAW-HW

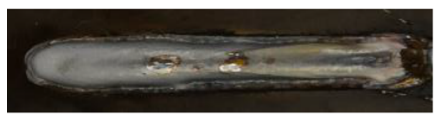
2D arc deflection (rotation)

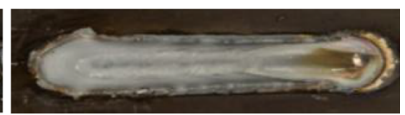

Fig. 16 External joint analysis of different GMAW hot wire processes with and without two-dimensional arc deflection during deposition welding two-dimensional arc deflection. At first, the electromagnetic behaviour of the developed demonstrator with integrated coil system was investigated. The results show a significant fluctuation of the magnetic induction depending on the position inside the magnetic field. The vertical distance along the electrode axis has a higher influence on the magnetic field than the lateral distance. In addition, it could be shown using Schlieren technology and oxygen concentration measurements that the two-dimensional arc deflection leads to an increased formation of turbulences of the shielding gas flow. In case of a rotation of the arc, circular frequencies up to $20 \mathrm{~Hz}$ influence the shielding gas coverage, but the valid oxygen concentration of $50 \mathrm{ppm}$ can still be maintained. Circular frequencies above $70 \mathrm{~Hz}$ should be avoided, since the inductivity of the coils prevents a sufficient magnetic arc deflection. Furthermore, numerical simulations including a GMAW hot wire process were used to calculate the heat input. It could be proven that a two-dimensional arc deflection can increase the heat input through the arc, since the contact surface between arc and base material is increased. These results could be confirmed by experimental investigations. It became obvious that an arc deflection longitudinal to the travel direction and an additional oscillating transverse deflection improve the wetting behaviour and increase the penetration depth at the same time. Further investigations 
Fig. 17 Process behaviour and macrostructure using twodimensional arc deflection for GMAW hot wire welding of a butt joint with Y-seam preparation

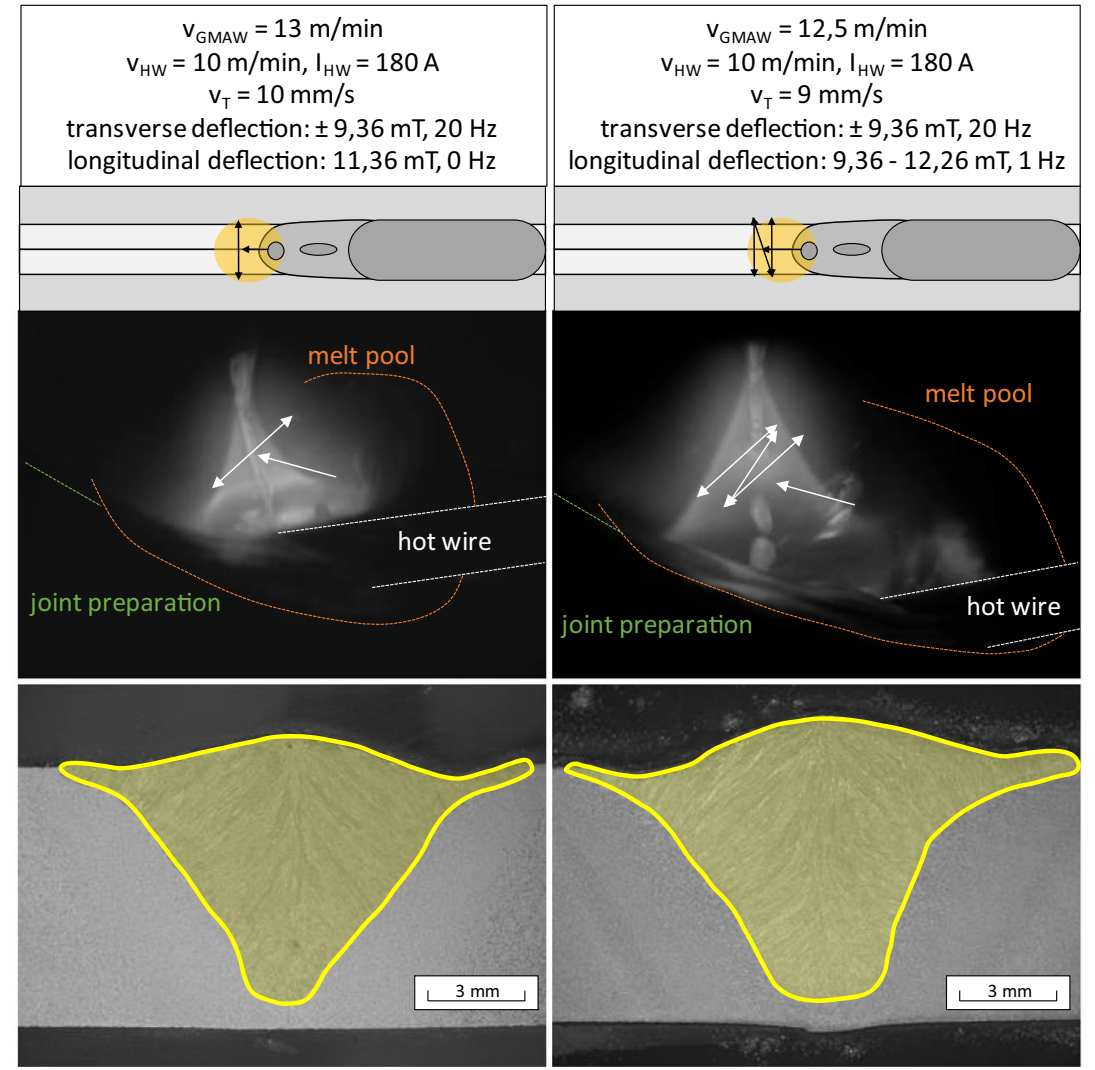

will take a base material out of high strength steel into account. Finally, the applicability of presented technology for multilayer welding will be examined.

Acknowledgements Open Access funding provided by Projekt DEAL.

Funding information The presented results are part of the IGF-funded research project "Highly productive GMAW joint welding by the use of an additional hot wire and a magnetic two-dimensional arc deflection (HighProd)" (IGF20156BR). We are grateful for this support.

Open Access This article is licensed under a Creative Commons Attribution 4.0 International License, which permits use, sharing, adaptation, distribution and reproduction in any medium or format, as long as you give appropriate credit to the original author(s) and the source, provide a link to the Creative Commons licence, and indicate if changes were made. The images or other third party material in this article are included in the article's Creative Commons licence, unless indicated otherwise in a credit line to the material. If material is not included in the article's Creative Commons licence and your intended use is not permitted by statutory regulation or exceeds the permitted use, you will need to obtain permission directly from the copyright holder. To view a copy of this licence, visit http://creativecommons.org/licenses/by/4.0/.

\section{References}

1. DVS - Deutscher Verband für Schweißen und verwandte Verfahren (2003) DVS-Merkblatt DVS 0909-2 - Grundlagen des MSGHochleistungsschweißen mit Massivdrahtelekt-roden anwendungstechnische Hinweise

2. Häßler M et al (2016) The influence of arc interactions and a central filler wire on shielding gas flow in tandem GMAW. Welding in the World 60(4):713-718

3. Arita $\mathrm{H}$ et al (2009) Development of advanced 3-electrode MAG high-speed horizontal fillet welding process. Welding in the World 53(5):35-43

4. Fang $\mathrm{C}$ et al (2012) TANDEM and GMAW twin wire welding of Q690 steel used in hydraulic support. Journal of Iron and Steel Research 19(5):79-85

5. Xiang T et al (2016) Effects of filling status of cold wire on the welding process stability in twin-arc integrated cold wire hybrid welding. International Journal of Advanced Manufacturing Technology 83(9):1583-1593

6. DVS - Deutscher Verband für Schweißen und verwandte Verfahren (2015) DVS-Merkblatt 0973 - Übersicht der Prozessregelvarianten des MSG-Schweißens

7. Costa Assunção PD et al (2017) Feasibility of narrow gap welding using the cold-wire gas metal arc welding (CW-GMAW) process. Welding in the World 61(4):659-666 
8. Marques LFN et al (2017) Fatigue life assessment of weld joints manufactured by GMAW and CW-GMAW processes. Science and Technology of Welding and Joining 22(2):87-96

9. Tsuyama Tet al (2014) Effects of hot wire on mechanical properties of weld metal using gas-shielded arc welding with $\mathrm{CO} 2$ gas. Welding in the World 58(1):77-83

10. Günther K et al (2018) Hot wire-assisted gas metal arc welding of hypereutectic $\mathrm{FeCrC}$ hardfacing alloys: microstructure and wear properties. Surf Coat Technol 334:420-428

11. Krehl P et al (1995) August Toepler - the first who visualized shock waves. Shock Waves 5(1-2):1-18

12. Schnick M et al (2012) Visualisierung der Schutzgasabdeckung beim Lichtbogenschweißen. Dresdner Fügetechnisches Kolloquium, p $7 \mathrm{ff}$

13. Schnick M et al (2012) Visualization and optimization of shielding gas flows in arc welding. Welding in the World 56(1-2):54-61
14. Scheer H et al (2001) Sensorelement zur Bestimmung der Sauerstoffkonzentration in Gas-gemischen und Verfahren zur Herstellung des-selben. Patent DE19941051A1

15. Hertel M, Füssel U, Rose S, Uhrlandt D (2014) Influence of different shielding gases on material transfer and arc properties in GMA welding, In: 67th IIW Annual Assembly, Study Group 212, Seoul, IIW-Doc.212-1335-14

16. Hertel M, Jäckel S, Spille-Kohoff A, Füssel U, Rose S (2013) Numerical simulation of radiative transfer in GMAW, In: 66th IIW Annual Assembly, Study Group 212, Essen, IIW-Doc.2121294-13

17. Lowke JJ, Tanaka M (2008) The physics of non-thermionic cathodes of electric arcs. In: 17th International Conference on Gas Discharges and Their Applications, Cardiff, UK

Publisher's note Springer Nature remains neutral with regard to jurisdictional claims in published maps and institutional affiliations. 